\title{
A Crossover Comparative Study to Assess Efficacy of 5\% vs. 20\% Albumin in the Treatment of Anasarca in Children with Idiopathic Nephrotic Syndrome
}

\author{
Ajoy Kumar Garg ${ }^{1}$, Suprita Kalra ${ }^{1}$, Ashutosh Kumar ${ }^{1}$ and Madhuri Kanitkar ${ }^{2}$ \\ ${ }^{1}$ Department of Paediatrics, Army Hospital (Research and Referral), New Delhi, India \\ ${ }^{2}$ DCIDS Medical, New Delhi, India
}

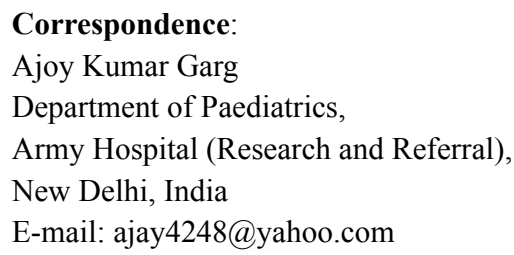

Correspondence:

Ajoy Kumar Garg

Department of Paediatrics,

Army Hospital (Research and Referral),

New Delhi, India

E-mail: ajay4248@yahoo.com

DOI: $10.3126 /$ jnps.v40i3.29110

Submitted on: $2020-05-25$

Accepted on: 2020-10-02

Acknowledgements: None

Funding: Nil

Conflict of Interest: None declared

Permission from IRB: Yes

To cite this article: Garg AK, Kalra S, Kumar A, Kanitkar M. A crossover comparative study to assess efficacy of $5 \%$ vs. $20 \%$ albumin in the treatment of anasarca in children with idiopathic nephrotic syndrome. J Nepal Paediatr Soc. 2020;40(3):157-63.

\section{ABSTRACT}

Introduction: Co-administration of albumin and furosemide has shown better response than furosemide alone in managing anasarca among children with nephrotic syndrome. There are different concentrations of albumin available. The aim of this study was to compare diuretic response to co-administration of either $5 \%$ or $20 \%$ albumin with furosemide in these children.

Methods: It was a crossover randomised trial conducted on children with nephrotic syndrome with moderate to severe oedema at a tertiary care centre. They were randomised to two groups; Group A $(n=14)$ received $5 \%$ albumin along with furosemide in midway followed by $20 \%$ albumin after washout period of $48 \mathrm{hrs}$ and group $\mathrm{B}(\mathrm{n}=10)$ received albumin vice versa. Baseline and post therapy vitals, fluid intake, urine output and biochemistry were noted. Primary outcomes were increase in urine output and reduction in weight following co-administration of albumin with furosemide. For analysis of primary outcomes, two interventional arms were formed; group I (5\% Albumin co-administered with furosemide) and group II (20\% Albumin co-administered with furosemide).

Results: Total children were 24 in each arm i.e. group I and II. Eighteen $(75 \%)$ were males. Mean (range) age at enrolment and duration of illness were $55.3(15-144)$ and $18.6(1-120)$ months respectively. Mean difference (SD) in urine output were 1.52 (1.11) and $1.66(0.95) \mathrm{ml} / \mathrm{kg} / \mathrm{hr}(\mathrm{p}=0.12)$ and mean percentage weight loss were $2.25 \%(2.12)$ and $3.68 \%(3.84)$ in group I and II respectively $(\mathrm{p}=0.64)$. On further comparing, urine output was significantly better when $5 \%$ albumin was co-administered with furosemide during first period than in second period.

Conclusions: Co-administration of either $5 \%$ or $20 \%$ albumin with furosemide is equally safe and effective in increasing urine output in children with anasarca.

Keywords: albumin; diuretic; nephrotic syndrome; oedema; urine output

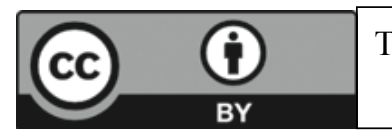

This work is licensed under creative common attribution 3.0 license 


\section{INTRODUCTION}

There are different theories behind the pathogenesis of oedema in nephrotic syndrome. ${ }^{1}$ As per under filling theory, nephrotic syndrome is a state of intravascular volume depletion. ${ }^{2}$ It activates renin angiotensin aldosterone pathway and causes increase sodium and water reabsorption at distal tubules to cause oedema. ${ }^{3-4}$ Other theory is overfill theory as per which primary defect lies in the kidney, which causes an increase in absorption of sodium and water and hence causes oedema in nephrotic syndrome. ${ }^{5}$ Since treatment with corticosteroids usually leads to diuresis within five to 10 days, diuretic is avoided unless oedema is significant. ${ }^{6-7}$

Diuretic is the standard therapy for treating moderate to severe oedema in children with nephrotic syndrome. Disadvantage of prolonged use of diuretic is that it can lead to electrolytes disturbance, aggravate the hypovolemic state and causes resistance to its diuretic effect. ${ }^{8}$ Infusion of albumin increases the plasma oncotic pressure and plasma volume which in turn increases the glomerular filtration rate. Improved GFR results in reduction of sodium and water re-absorption at proximal tubules and increases delivery of both to the distal nephrons which restores the capacity to respond to diuretics. ${ }^{9,10}$ Albumin also increases the bioavailability of furosemide by improving serum albumin level. ${ }^{11-15}$

Human albumin is available in different concentrations like 5\%,20\% and 25\%. 5\% human albumin is isotonic to plasma whereas $20 \%$ and $25 \%$ albumin solutions are hypertonic. Few studies have shown better diuretic response to coadministration of albumin along with furosemide than furosemide alone. These studies have used hypertonic albumin solution in children with hypoalbuminemic state. As nephrotic syndrome is usually a state of volume contraction and hypotonic state, theoretically an infusion of $5 \%$ albumin at same dose as other forms of albumin in larger volume will not only improve serum albumin and plasma oncotic pressure but will also improve intravascular volume immediately. On the other hand, hypertonic albumin colloid improves plasma oncotic pressure better than $5 \%$ albumin. Use of any albumin to improve diuretic response is an expensive therapy. Hence it is to be used judiciously. We designed randomised cross-over trial to compare the diuretic effect of coadministration of $5 \%$ (isotonic) or $20 \%$ (hypertonic) albumin along with furosemide in children with nephrotic syndrome with moderate to severe oedema.

\section{METHODS}

This prospective, single centre, randomised crossover trial was conducted in a tertiary care hospital in India from Jan 2008 to Jan 2010 to compare the diuretic effect of co-administration of either $5 \%$ or $20 \%$ albumin along with furosemide in children with nephrotic syndrome with moderate to severe oedema. The study was approved by the Institutional Research Review and Ethics Committee. Written parental consent was obtained. Children more than one year of age with nephrotic syndrome presenting with moderate to severe oedema defined by anasarca, pulmonary effusion, ascites, scrotal or vulvar oedema were included in the study. Children with mild oedema or spontaneously resolving oedema, nephrotic syndrome secondary to SLE, viral hepatitis, haemolytic uremic syndrome, infectious disease, congenital nephrotic syndrome, sepsis, renal failure or insufficiency and on diuretics or steroid during study period were excluded.

After enrolment, children were randomised as per computer generated randomisation in two groups; Group A $(\mathrm{n}=14)$ received 5\% albumin along with furosemide in midway in first period and $20 \%$ albumin in second period with wash out period of $48 \mathrm{hrs}$ and vice versa in group $\mathrm{B}(\mathrm{n}=10)$. Demographic, clinical profile, baseline urine output and fluid intake, weight, serum urea, creatinine, albumin, sodium, potassium and urinary creatinine, sodium and potassium were computed as per protocol. Albumin was infused at a dose of $1 \mathrm{~g} / \mathrm{kg}$ over four hours, furosemide was administered at a dose of $2 \mathrm{mg} / \mathrm{kg}$ intravenously midway. Post coadministration of albumin and furosemide, serum albumin, urea, creatinine, sodium, potassium and urinary creatinine, sodium and potassium were sent. Fluid intake, urine output over 24 hours and weight were re-measured after 24 hours. After 


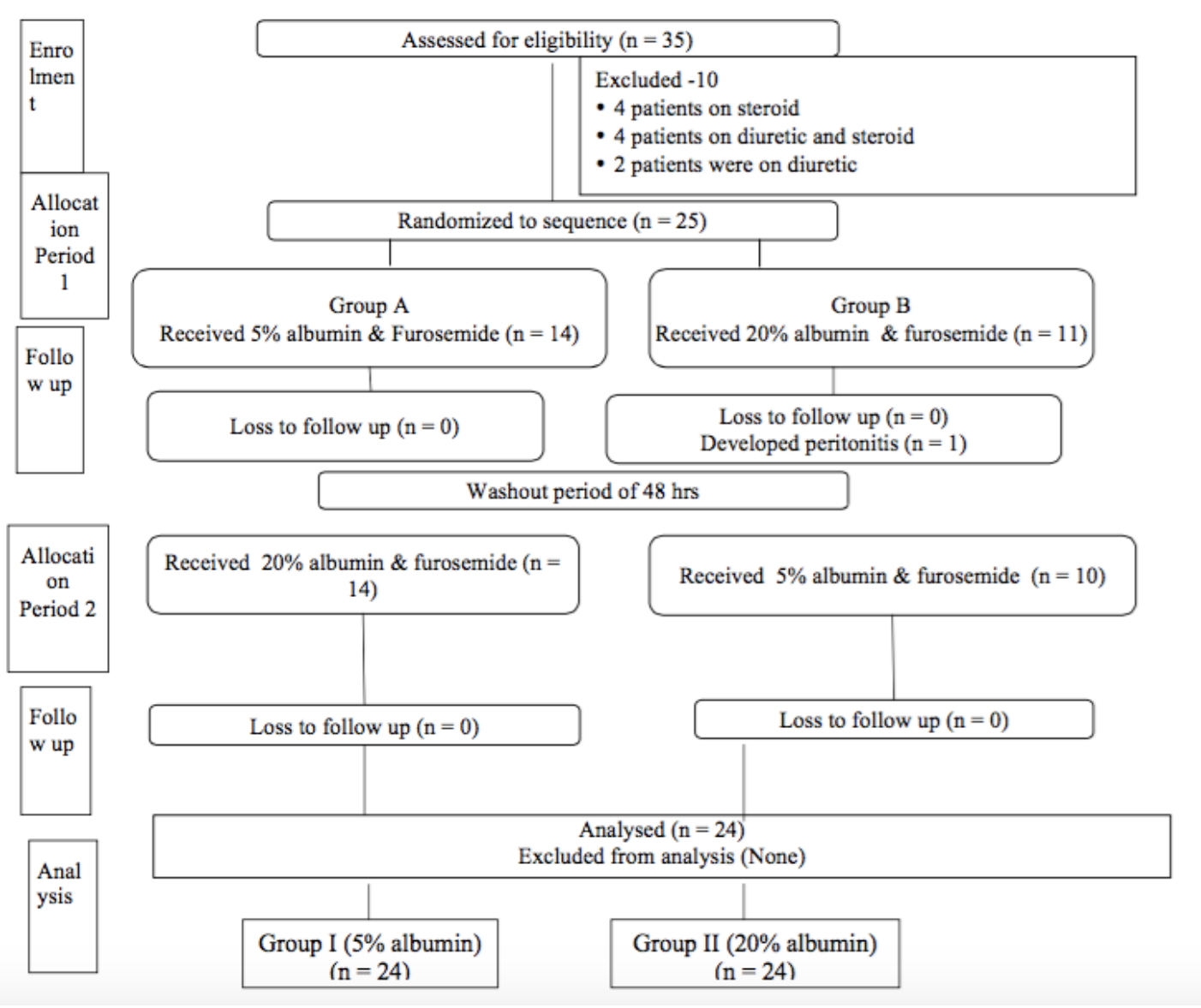

Figure 1. Flow of participants through each stage

washout period of 48 hours, again baseline parameters were repeated and other form of albumin was co-administered with furosemide as described. Finally, each subject received both 5\% and $20 \%$ albumin along with furosemide. For analysis of primary outcomes, two interventional arms were formed; group I and group II receiving $5 \%$ and $20 \%$ albumin respectively. Primary outcomes studied were weight loss and increase in urine output and secondary outcomes studied were $\mathrm{FeNa}$ and urinary potassium index. The outcomes were calculated and recorded for both groups I and II. Complications related to albumin infusion like hypertension, pulmonary oedema, need for dialysis or ventilation was also recorded during the study period.

Based on our pilot study $(\mathrm{n}=10)$, we found mean (SD) urine output $2.9(0.8) \mathrm{ml} / \mathrm{kg} / \mathrm{hr}$ and $2.2(1.0)$ $\mathrm{ml} / \mathrm{kg} / \mathrm{hr}$ post $5 \%$ and $20 \%$ albumin respectively. Taking power of $80 \%$ and $\alpha$ error of 0.05 , and allocation of $1: 1$, we estimated sample size of 27 children in each arm. Patient, data recorder and statistician were blinded to concentration of albumin used. Analysis was done by intention to treat. Data were presented as number (\%) or mean (SD), median (CI) or range as appropriate. Results were analysed using IBM SPSS statistics 17. Quantitative data with normal distribution were compared using student t-test and those with skewed distribution were analysed using Mann Whitney $U$ test and Wilcoxon signed rank test for related sample. Categorical data was compared using Chi square or Fisher exact test as applicable. The $\mathrm{p}$ value $<0.05$ was taken as statistically significant.

\section{RESULTS}

During the study period, 35 children with nephrotic syndrome with moderate to severe oedema were eligible but 10 children were excluded before randomisation and one was excluded after 
randomisation due to various reasons as shown in figure 1. Eighteen (75\%) patients enrolled were males. Mean (range) age at enrolment and duration of illness were 55.3 (15 - 144) months and 18.6 (1 120) months respectively. Clinical profile of children with nephrotic syndrome at enrolment has been depicted in Table 1. As each child received both forms of albumin, total children were 24 in each arm i.e. group I (5\% albumin) and II (20\% albumin). In group I, 14 children received 5\% albumin in the first period and 10 children in the second period. In group II, 10 children received $20 \%$ albumin in the first period and 14 children in the second period. Baseline parameters like weight, urine output, fluid intake, serum albumin, FeNa and urinary potassium index in both groups I and II were comparable (Table 2). Post albumin transfusion, serum albumin and fluid intake in both groups I and II were also comparable. There was a significant increase in urine output, sodium excretion and decrease in urinary potassium index post therapy, as compared to baseline in both the groups (Table 2). But there was no significant mean difference in weight loss or urine output between group I (5\% albumin) and group II (20\% albumin). Mean difference (SD) in urine output was 1.52 (1.11) and $1.66(0.95) \mathrm{ml} / \mathrm{kg} / \mathrm{hr}(\mathrm{p}=0.12)$ and mean percentage weight loss was 2.25 (2.12) and 3.68 (3.84) \% in groups I and II respectively $(p=0.64)$. Mean difference in albumin, FeNa and potassium excretion index in both groups were also comparable (Table 3).
Table 1. Demographic and clinical profile at presentation $(\mathrm{n}=24)$

\begin{tabular}{|lr}
\hline Parameters \\
\hline Age at enrolment* & $55.3(15-144)$ \\
Age at onset* & $36.7(12-98)$ \\
Duration of illness* & $18.6(01-120)$ \\
Gender distribution (M : F) & $3: 1$ \\
Course of illness & $10(41.7 \%)$ \\
\multicolumn{1}{|c}{ First } & $07(29.2 \%)$ \\
$\quad$ Infrequent relapse & $04(16.7 \%)$ \\
Frequent relapse & $02(8.3 \%)$ \\
Steroid dependent & $01(4.2 \%)$ \\
Steroid resistant &
\end{tabular}

*Data are expressed in months (Mean, range)

On further comparing group A $(\mathrm{n}=14)$ and group B $(n=10)$, urine output was significantly better when $5 \%$ albumin was co-administered with furosemide during $1^{\text {st }}$ period in group A than in second period in group B. There was no statistically significant difference in urine output in both periods in case of $20 \%$ albumin. But mean increase in urine output was better for $20 \%$ albumin in both periods $(2.38$ and $1.4 \mathrm{ml} / \mathrm{kg} / \mathrm{hr})$ than $5 \%$ albumin ( 2.07 and $1.12 \mathrm{ml} / \mathrm{kg} / \mathrm{hr}$ ), although difference was not statistically significant $(\mathrm{p}=0.5$ and 0.4 respectively) (Table 4).

Table 2. Comparisons of parameters before and after therapy in group I (5\% albumin co-administered with furosemide) and group II (20\% albumin co-administered with furosemide)

\begin{tabular}{|lrrrrrr|}
\hline & \multicolumn{2}{c}{ Group I $(\mathbf{n}=\mathbf{2 4})$} & p value & \multicolumn{2}{c}{ Group II (n= 24) } & P value \\
\cline { 2 - 7 } & \multicolumn{1}{c}{ Baseline } & $\begin{array}{c}\text { Post- } \\
\text { transfusion }\end{array}$ & & Baseline & \multicolumn{1}{c}{$\begin{array}{c}\text { Post- } \\
\text { transfusion }\end{array}$} \\
\hline Weight $(\mathrm{Kg})$ & $18.6(7.9)$ & $18.2(8.01)$ & 0.8 & $18.7(8.1)$ & $18.0(8.03)$ & 0.7 \\
Urine output $(\mathrm{ml} / \mathrm{kg} / \mathrm{hr})$ & $1.1(0.72)$ & $2.63(1.32)$ & $<0.01$ & $1.17(1.0)$ & $2.84(1.3)$ & $<0.01$ \\
Fluid intake $(\mathrm{ml} / \mathrm{kg} / \mathrm{day})$ & $34.3(16.8)$ & $42.7(27.3)$ & 0.2 & $33.3(22.0)$ & $45.2(31.1)$ & 0.13 \\
Serum albumin $(\mathrm{g} / \mathrm{dl})$ & $2.0(0.24)$ & $3.98(0.49)$ & $<0.01$ & $2.1(0.26)$ & $3.9(0.46)$ & $<0.01$ \\
FeNa $(\%)$ & $0.77(0.65)$ & $1.91(1.71)$ & $<0.01$ & $0.73(0.74)$ & $1.73(2.2)$ & 0.04 \\
Urinary $\mathrm{K}^{+} / \mathrm{K}^{+}+\mathrm{Na}^{+}$ & $0.52(0.10$ & $0.42(1.3)$ & $<0.01$ & $0.51(0.11)$ & $0.41(0.09)$ & $<0.01$
\end{tabular}

Data are expressed as mean (SD); $p$ value $<0.05$ is taken as significant; $\mathrm{FeNa}$ (Fractional excretion of sodium), Urinary $\mathrm{K}^{+} / \mathrm{K}^{+}$ $+\mathrm{Na}^{+}$:urinary potassium index. $\mathrm{P}$ Value for baseline parameter were $<0.05$ 
Table 3. Comparisons of mean difference in parameters between pre and post treatment in group I (5\% albumin) and group II (20\% albumin)

\begin{tabular}{|c|c|c|c|}
\hline & $\begin{array}{l}\text { Group I } \\
(n=24)\end{array}$ & $\begin{array}{l}\text { Group II } \\
(n=24)\end{array}$ & $\begin{array}{l}\mathbf{p} \\
\text { value }\end{array}$ \\
\hline Serum albumin (g/dl) & $\begin{array}{l}0.91 \\
(0.37)\end{array}$ & $0.81(0.46)$ & 0.4 \\
\hline $\begin{array}{l}\text { Urine output (ml/kg/ } \\
\text { hr) }\end{array}$ & $\begin{array}{l}1.52 \\
(1.11)\end{array}$ & $1.66(0.95)$ & 0.6 \\
\hline Weight loss (\%) & $\begin{array}{l}2.25 \\
(2.12)\end{array}$ & $3.68(3.84)$ & 0.1 \\
\hline $\mathrm{FeNa}(\%)$ & $\begin{array}{l}1.14 \\
(1.47)\end{array}$ & $1.0(1.97)$ & 0.7 \\
\hline Urinary $\mathrm{K}^{+} / \mathrm{K}^{+}+\mathrm{Na}^{+}$ & $0.1(0.19)$ & $0.1(0.12)$ & 1 \\
\hline
\end{tabular}

There were no complications related to plasma volume overload like hypertension, pulmonary oedema, need for dialysis or ventilation following administration of either $5 \%$ or $20 \%$ albumin during the study period.

\section{DISCUSSION}

In 1974 Davison AM et al. ${ }^{16}$ studied human albumin in the management of nephrotic syndrome and concluded that $15 \%$ albumin in conjugation with frusemide are of value in treating patients with nephrotic syndrome. Similarly, in $2001 \mathrm{~K}$ Young et al. ${ }^{17}$ used $20 \%$ albumin with frusemide, which was also effective in increasing urine output. Weiss et al. ${ }^{18}$ and Bircan et al. $^{19}$ demonstrated weight reduction with use of combination therapy. However, this beneficial effect was transient. These authors had used hypertonic albumin $(15,20,25 \%)$ rather than isotonic albumin (5\%). To compare the diuretic effect of isotonic and hypertonic albumin we used $5 \%$ and $20 \%$ albumin respectively which was administered along with furosemide among children with nephrotic syndrome with moderate to severe oedema and found that there was significant increase in urine output following coadministration of furosemide and either form of albumin. On comparing the mean difference in urine output and weight loss from baseline in each arm, there was no statistical difference in both forms of therapy.

We observed that use of 5\% albumin along with furosemide in first period had significantly better urine output compared to second period but there was no significant difference with $20 \%$ albumin. Simultaneously we also observed that mean increase in urine output was better for $20 \%$ albumin in both periods 1 and $2(2.38$ and $1.4 \mathrm{ml} / \mathrm{kg}$ respectively) than 5\% albumin $(2.07$ and $1.12 \mathrm{ml} /$ $\mathrm{kg} / \mathrm{hr}$ respectively) although these differences were not statistically significant $(\mathrm{p}=0.5$ and 0.4 respectively). Hence, use of 5\% albumin in first period was significantly higher than in second period but there was no significant mean difference in urine output between $5 \%$ and $20 \%$ albumin in both periods.

Ghafari et al. ${ }^{20}$ in 2011 demonstrated that coadministration of albumin and furosemide caused

Table 4. Comparison of urine output and weight in group A and group B during period 1 and period 2

\begin{tabular}{|c|c|c|c|c|c|c|}
\hline & \multicolumn{3}{|c|}{$5 \%$ albumin } & \multicolumn{3}{|c|}{$20 \%$ albumin } \\
\hline & $\begin{array}{c}\text { Group A } \\
(n=14) \\
\text { Period } 1\end{array}$ & $\begin{array}{c}\text { Group B } \\
(n=10) \\
\text { Period } 2\end{array}$ & P value & $\begin{array}{c}\text { Group B } \\
(\mathrm{n}=10) \\
\text { Period } 1\end{array}$ & $\begin{array}{c}\text { Group A } \\
(n=14) \\
\text { Period } 2\end{array}$ & P value \\
\hline $\begin{array}{l}\text { Baseline urine output } \\
(\mathrm{ml} / \mathrm{kg} / \mathrm{hr}) \text { mean }(\mathrm{SD})\end{array}$ & $0.86(0.44)$ & $1.45(0.97)$ & 0.1 & $0.88(0.74)$ & $1.49(1.13)$ & 0.1 \\
\hline $\begin{array}{l}\text { Baseline weight } \\
\text { (kg), mean ( SD) }\end{array}$ & $18.75(9.0)$ & $18.3(8.9)$ & 0.9 & $19.4(7.8)$ & $18.2(8.9)$ & 0.7 \\
\hline *Urine output (ml/kg/hr) & $2.07(1.22)$ & $1.12(0.43)$ & 0.01 & $2.38(1.24)$ & $1.4(1.2)$ & 0.06 \\
\hline Weight loss $(\%)$ mean (SD) & $2.38(2.1)$ & $2.06(2.2)$ & 0.7 & $4.6(4.1)$ & $3.0(3.5)$ & 0.3 \\
\hline
\end{tabular}

* Mean difference in urine output between baseline and post co-administration of albumin with furosemide 
an increase in urine volume and sodium excretion when compared to furosemide alone. In another study, Dharmaraj et al. ${ }^{21}$ evaluated 16 children with nephrotic syndrome and refractory oedema in a randomised cross-over trial to receive either combination therapy or furosemide alone. The results from this study suggests a short-term positive effect of combination therapy on diuresis and natriuresis. We also found that post coadministration of albumin and furosemide, there was an increase in $\mathrm{FeNa}$ and decrease in urinary potassium index. We know that the urinary potassium index (urinary $\mathrm{K}^{+} / \mathrm{K}^{+}+\mathrm{Na}^{+}$) and $\mathrm{FeNa}$ are satisfactory indices of activation of the renin angiotensin-aldosterone axis. Patients with nephrotic syndrome and hypovolemia typically show low FeNa (often below 0.2\%) and high urinary $\mathrm{K}^{+} / \mathrm{K}^{+}+\mathrm{Na}^{+}$(ratio greater than 0.6 ). ${ }^{22,23}$ Our study also shows the same, thereby highlighting that nephrotic syndrome is state of prerenal dehydration or hypovolemia which improves after albumin infusion.

This was a prospective, cross-over, randomised trial, where children with idiopathic nephrotic syndrome with oedema were enrolled after excluding possible secondary causes of nephrotic syndrome. Patient, data recorder and statistician were blinded. But there were also a few limitations in our study like treating clinician was not blinded, sample size was relatively small and it was a single centric study. For further analysis, whether the use of $5 \%$ albumin in $1^{\text {st }}$ period or sequential use of $5 \%$ and $20 \%$ albumin is a better option than the use of either $5 \%$ or $20 \%$ albumin in moderate to severe oedema should be done after larger, multi-centric trials in the future.

\section{CONCLUSIONS}

Treatment of moderate to severe oedema due to nephrotic syndrome may require the use of albumin along with diuretic if diuretics alone do not yield adequate results. Both $5 \%$ or $20 \%$ albumin when co-administered with furosemide are equally safe and effective in improving urine output in children with moderate to severe oedema in nephrotic syndrome.

\section{REFERENCES}

1. Palmer BF, Alpern RJ. Pathogenesis of oedema formation in the nephrotic syndrome. Kidney Int Suppl. 1997;59:21-7. PMID: 9185099

2. Vande Walle JG, Donckerwolcke RA. Pathogenesis of oedema formation in the nephrotic syndrome. Pediatr Nephrol. 2001;16(3):283-93. DOI: https://doi.org/10.1007/s004670000512

3. Usberti M, Federico S, Meccariello S, Cianciaruso B, Balletta M, Pecoraro C, et al. Role of plasma vasopressin in the impairment of water excretion in nephrotic syndrome. Kidney Int. 1984;25(2):422-9. https://doi.org/10.1038/ki. 1984.34

4. Kumagai H, Onoyama K, Iseki K, Omae T. Role of renin angiotensin aldosterone on minimal change nephrotic syndrome. Clin Nephrol. 1985;23(5):229-35. PMID: 4006331

5. Schrier RW, Fassett RG. A critique of the overfill hypothesis of sodium and water retention in the nephrotic syndrome. Kidney Int. 1998;53:1111-17. https://doi.org/10.1046/j.1523-1755.1998.00864.x

6. Srivastava RN, Bagga A. Nephrotic syndrome. In: Paediatric Nephrology. 4th edition. New Delhi: Jaypee Brothers; 2005. p. 161-200.

7. Vogt AB, Avner ED. Nephrotic syndrome. In: Nelson Textbook of Paediatrics. 18th edition. Kliegman RM, Behrman RE, Jenson HB, Stanton BF, editors. Philadelphia: WB Saunders; 2007. p2190-95.

8. Kirchner KA, Voelker JR, Brater DC. Intratubular albumin blunts the response to furosemide: A mechanism for diuretic resistance in the nephrotic syndrome. J Pharmacol Exp Ther. 1990;252:1097-101. PMID: 2319462 
9. Knox FG. Effect of increased proximal delivery on frusemide natriuresis. Am J Physiol. 1970;218(3):819-23. DOI: https://doi.org/10.1152/ajplegacy.1970.218.3.819.

10. Brenner BM, Falchuk KH, Keimowitz RI, Berliner RW. The relationship between peritubular capillary protein concentration and fluid reabsorption by the renal proximal tubule. J Clin Invest. 1969;48(8):1519-31. DOI: https:// doi.org/10.1172/JCI106118.

11. Haws RM, Baum M. Efficacy of albumin and diuretic therapy in children with nephrotic syndrome. Paediatrics. 1993;91(6):1142-6. PMID: 8502517

12. Akcicek F, Yalniz T, Basci A, Ercan OK, Mees ED. Diuretic effect of frusemide in patients with nephrotic syndrome: is it potentiated by intravenous albumin? BMJ. 1995;310:162-3. DOI: https://doi.org/10.1136/bmj. 310.6973.162.

13. Dorhout Mees EJ. Does it make sense to administer albumin to the patient with NS. Nephrol Dial Transplant. 1996; 11:1224-6. DOI: https://doi.org/10.1093/ndt/11.7.1224.

14. Fliser D, Zurbrüggen I, Mutschler E. Co-administration of albumin and furosemide in patients with the nephrotic syndrome. Kidney Int. 1999;55(2):629-34. DOI: https://doi.org/10.1046/j.1523-1755.1999.00298.x.

15. Elwell RJ, Spencer AP, Eisele G. Combined furosemide and human albumin treatment for diuretic-resistant oedema. Ann Pharmacother.; 37(5):695-700. DOI: https://doi.org/10.1345/aph.1C320

16. Davison AM, Lambie AT, Verth AH, Cash JD. Salt- poor Human Abumin in management of Nephrotic Syndrome. Brit Med J. 1974;i:481-4. https://doi.org/10.1136/bmj.1.5906.481

17. Na KY, Han JS, Kim YS, Ahn C, Kim S, Lee JS, et al. Does Albumin Preinfusion Potentiate Diuretic Action of Furosemide in Patients with Nephrotic Syndrome? J Korean Med Sci. 2001;16:448-54. DOI: https://doi.org/ 10.3346/jkms.2001.16.4.448 .

18. Weiss RA, Schoeneman M, Greifer I. Treatment of severe nephrotic oedema with albumin and furosemide. N. Y. State J. Med. 1984;84:384-6. PMID: 6592472

19. Bircan Z, Kervancioglu M, Katar S, Vitrinel A. Does albumin and furosemide therapy affect plasma volume in nephrotic children? Pediatr Nephrol. 2001; 16:497-9. DOI: https://doi.org/10.1007/s004670100576.

20. Ghafari A, Mehdizadeh A, Alavi-Darazam I, Rahimi E, Kargar C, Sepehrvand N. Co-administration of albuminfurosemide in patients with the nephrotic syndrome. Saudi J Kidney Dis Transpl. 2011;22(3):471-5. PMID: 21566302

21. Dharmaraj R., Hari P., Bagga A. Randomized cross-over trial comparing albumin and frusemide infusions in nephrotic syndrome. Pediatr Nephrol. 2009; 24:775-82. DOI: https://doi.org/10.1007/s00467-008-1062-0.

22. Kapur G, Valentini RP, Imam AA, Mattoo TK. Treatment of severe oedema in children with nephrotic syndrome with diuretics alone: A prospective study. Clin J Am Soc Nephrol. 2009;4:907-13. DOI: https://doi.org/10.2215/ CJN.04390808.

23. Donckerwolcke RA, France A, Raes A, Vande Walle J. Distal nephron sodium-potassium exchange in children with nephrotic syndrome. Clin Nephrol. 2003;59:259-66. DOI: https://doi.org/10.5414/CNP59259 